\title{
Multi-objective Tubular Hydroforming Process Parametric Optimization using TOPSIS and PSI techniques
}

Pathapalli Venkateshwar Reddy ( $\nabla$ mr.pvreddy@gmail.com )

Vardhaman College of Engineering https://orcid.org/0000-0002-1012-7510

B. Veerabhadra Reddy

G Pulla Reddy College of Engineering and Technology

\section{Research Article}

Keywords: Tube Hydroforming, MCDM, TOPSIS, PSI, Entropy, Bulging, Thinning Ratio, Bulge pressure, SS 304, lubrication

Posted Date: November 2nd, 2021

DOI: https://doi.org/10.21203/rs.3.rs-866901/v1

License: (c) (i) This work is licensed under a Creative Commons Attribution 4.0 International License.

Read Full License 


\title{
Multi-objective Tubular Hydroforming Process Parametric Optimization using TOPSIS and PSI techniques
}

\author{
P. Venkateshwar Reddy ${ }^{*}$, B. Veerabhadra Reddy ${ }^{2}$ \\ ${ }^{1 *}$ Department of Mechanical Engineering, Vardhaman College of Engineering, Shamshabad, \\ Telangana, INDIA-501218, E-Mail: mr.pvreddy@ vardhaman.org \\ ${ }^{2}$ Department of Mechanical Engineering, G Pulla Reddy Engineering College, Kurnool, A.P., \\ INDIA-518007
}

\begin{abstract}
Tube Hydroforming (THF) process is widely used in the aerospace and automotive industries. The success of forming tubular components using the THF process generally depends on many influencing parameters such as geometry, coefficient of friction, loading pathways, material formability, etc. The objective of this study was to determine the effect of the corner radius, coefficient of friction and heat treatment temperature on the bulging of the tubular component using finite element simulations. To address the complexity of parameter selection correctly with different alternatives, the multi-criteria decision-making methods (MCDM) applied in the present work. Two decision models, namely Technique for Order Performance by Similarity to Ideal Solution (TOPSIS) and Performance Selection Index (PSI) methods with entropy weighting criteria were applied for obtaining the best combination of parameters to get a sound quality product. Finally, the proposed ranking was validated by conducting experimental trials and the error was observed to be in limits in comparison with the simulated data. ANOVA was also performed to distinguish the significant parameters and their contribution to the responses. Both the MCDM methods suggested the same favorable and unfavorable alternatives.
\end{abstract}

Keywords: Tube Hydroforming; MCDM; TOPSIS; PSI; Entropy; Bulging; Thinning Ratio; Bulge pressure; SS 304; lubrication

\section{Introduction}

Tube Hydroforming (THF) process is used widely for the production of tubular components especially in aerospace and automotive fields and also in household and general appliances manufacturing industries. The express growth of this process is due to the advantages which possess when compared to the conventional manufacturing techniques. THF possess the advantages like part consolidation; reduction in weight, scrap and secondary operations; improvement in structural strength and tolerance etc [1]. The successful forming depends on many factors like loading paths which include both axial feeding and internal pressure. Moreover, factors like material formability and lubrication conditions also affect the THF process [2]. An appropriate combination of all these parameters reduces the defects like wrinkling and buckling during the process. Due to the importance of loading paths in THF process, many researchers investigated on 
the optimal process parameters selection. In the earlier years, Natal Jeorge et al. [3] investigated using a finite element model of tubular hydroforming processes with tailor-welded butt joint tubes with a constant diameter and varying thickness. As a result, the weld line impact on the fractures of the tubes was discussed in the study and also concluded that the numerical finite element-based tool can be used to reduce the thickness reduction at critical sections. Later, Fann \& Hsiao [4] worked on the conjugate gradient method for optimizing the loading trajectories for producing Tshaped components using THF process. Different modes were considered in their study but finally concluded that the optimization set of parameters generated by sequential mode attained better results. Aue-U-Lan et al. [5] compared different optimization techniques coupled with FE codes. Obtained results from different combinations were compared with experiments results and the best combination was highlighted in their study. In another work of Lin et al. [6] optimization of loading paths for dissymmetrical hydroformed components was investigated.

Manabe et al. [7] investigated the optimal loading paths in tube hydroforming using intelligent control techniques. Aluminum Al 6031-T6 was used as the tube material and by considering the internal pressure, feed rate and counter punch displacements as the input parameters in their study. It was concluded that the fuzzy control algorithm attained better results such that the failures in tube hydroforming was reduced. Mohammadi et al. [8] worked on the THF parametric optimization using neural networks combined with experimental results. Optimization techniques like hill climb search and simulated annealing were utilized to optimize the axial feeding and internal pressure to produce $\mathrm{T}$ shaped components using FE analysis. Obtained results from the optimization techniques combined with FE analysis were verified with experimental tests. Di Lorenzo et al. [9] developed a new optimization strategy called FEM-gradient based technique. The major aim of the work was to optimize the loading path and internal pressure during the tube hydroforming process. The developed technique predicted the optimized parameters and which were validated by the experimental results as well. Abedrabbo et al. [10] investigated the optimization method which was clubbed with FE analysis to find the formability limits of advanced high strength steels. Optimum loading paths and internal pressure using HEEDS optimization tool were reported to obtain better formability in the tube hydroforming process using LS-Dyna. Moreover, obtained results are validated by conducting experimental trials and are in good agreement. An et al. [11] worked towards the sensitivity analysis of the THF process variables and concurrent optimization was carried out to obtain a better product. Taguchi's based experimental design was utilized for performing experimental trials. LS-OPT were utilized to obtain the optimized process window, which was helpful for the improvement of product quality.

Mirzaali et al. [12] considered the forming parameters of tube hydroforming process to obtain better product by optimizing the parameters using a simulated annealing algorithm (SAA). The experiments were carried out by considering the obtained optimized forming parameters and good results were observed. Later, in another work, Seyedkashi et al. [13] considered tube dimensions to attain optimized pressure and loading paths using the same SAA. Moreover, the causes of diameter and thickness of the tube on the pressure and loading paths were discussed in their work. 
Teng et al. [14] explored on THF process to avoid the defects like wrinkling and buckling on the formed components by considering an adaptive simulation technique coupled to the fuzzy control method. The obtained optimized loading path attained sound T-Shaped component. Brooghani et al. [15] considered the multi-level RSM for optimizing THF process loading paths. Thickness variation and protrusion height were considered as the response variables and through the help of multi-level RSM better component was obtained and verified through the experimental results. Intarakumthornchai et al. [16] considered the genetic algorithm to optimize the loading paths to attain good fuel filler by tube hydroforming process. Huang et al. [17] worked on simultaneous optimization of T-Shaped components by utilizing dual response surface methodology. Response variables selected in their study were thinning and protrusion height and the best optimal combination of parameters were attained by the considered method. In another work, the authors considered the contact pressure of tube and counter punch as an additional parameter along with thinning ratio and protrusion height were considered to formulate the multi-objective problem [18]. Chebbah and Leebal [19] developed a new surrogate model to optimize the parameters like thinning variation and also the industrial requirements. The proposed approach established better tool dimensions and loading paths to attain sound final product. Ying-Ying et al. [20] worked on the optimization of loading paths by considering the geometrical parameters of $\mathrm{T}-$ Shaped tube hydroforming component. Other than loading paths, the authors considered backward displacement and frictional coefficient as also the effectible parameters to model the process. Influence of considered parameters was analyzed using response surface methodology and concluded that the backward displacement as one of the major factors which influences the circle angle radius.

In outline, the previous works were concentrated mostly on FE modeling and their corresponding validation by experimental trails considering the effect of loading paths in THF process for producing $\mathrm{X}, \mathrm{Y}, \mathrm{T}$ hydroforming components and other typical tubes formation. However, the additional significant parameters like frictional coefficient, geometrical constraints and heat treatment were neglected because of experimental circumstances.

The Taguchi method [21] is a common method used for optimizing the process variables. This technique uses orthogonal arrays to conduct the experiments and also utilizes the S/N ratios to compute the feature. Day by day developments was made to improve the success of the Taguchi technique. The major drawback of the technique is it optimizes only a single response at a time. But, in a real-time scenario, engineers need more than one response is required to optimize. In recent years, many methods were developed for optimizing multi-response problems. Choosing the most excellent option among diverse options is considered as a distinctive multi-criteria decision-making (MCDM) problem [22, 23]. Entropy is a method initiated to grade choices based on efforts from proficient judgments [24]. The compensation by means of entropy technique comprises of achieving improved properties, advanced quality result and shorter result improvement practice $[25,26]$. The TOPSIS is an MCDM technique based on the thought that the selected option be supposed to contain the shortest geometrical distance from the optimistic ideal 
result [27]. Other MCDM techniques particularly PSI scheme do not entail weight criterion, so the determination of weight norm is not essential [28]. Many industrial fields utilized MCDM techniques and the overview of such works can be found in publications [28, 29].

The literature studies concluded that MCDM methods were applied on many selection and decision making problems but the not used on processing parameters assortment of THF process has not been studied. Therefore, in this study, 27 numbers of experiments were conducted based on the full factorial design. Later, two different MCDM methods (i.e. Entropy-TOPSIS and PSI) were used for selecting the best alternatives concerning considered criterion. Eventually, several advantageous conclusions for the improvement of tube bulging during the THF process were clarified at the last part of this research work.

\section{Materials and Methods}

\subsection{Chemical Composition of Materials}

SS 304 sheets which are easily available and possess very high applications were used in the present study. The sheet of $1 \mathrm{~mm}$ thickness was procured from the market and utilized for the study. To confirm the material grade, the chemical composition was performed using wet chemical analysis and exposed in Table 1.

Table 1 Chemical composition of SS 304 material

\begin{tabular}{llllllllll}
\hline Elements & $\mathrm{Cr}$ & $\mathrm{Ni}$ & $\mathrm{Mn}$ & $\mathrm{C}$ & $\mathrm{Si}$ & $\mathrm{S}$ & $\mathrm{Al}$ & $\mathrm{Cu}$ & $\mathrm{Fe}$ \\
\hline $\begin{array}{l}\text { SS 304 } \\
\text { (wt. \%) }\end{array}$ & 18.91 & 8.44 & 1.79 & 0.015 & 0.483 & 0.03 & - & 0.043 & Balanced \\
\hline
\end{tabular}

\subsection{Tensile test}

Uni-axial tensile tests and r-bar tests were performed to evaluate the mechanical properties of procured SS 304 sheet metal in both as-received and heat-treated condition. ASTM E8/E8 M-09 standard was selected for performing tensile tests [30] and performed on INSTRON 3369 made universal testing machine which is having a capacity of $50 \mathrm{kN}$. The obtained stress-strain graph is shown in Fig. 1. A constant strain rate of $0.01 \mathrm{~mm} / \mathrm{sec}$ at room temperature was fixed for performing all the tensile tests on all the samples. R-bar tests were conducted to identify the plastic anisotropy of the sheet metal. Tests were conducted as per ASTM E517 standard in three different rolling directions $0^{\circ}, 45^{\circ}$ and $90^{\circ}$. The detailed R-bar test procedure can be found in the literature [31]. The obtained material properties data are exposed in Table 2. 


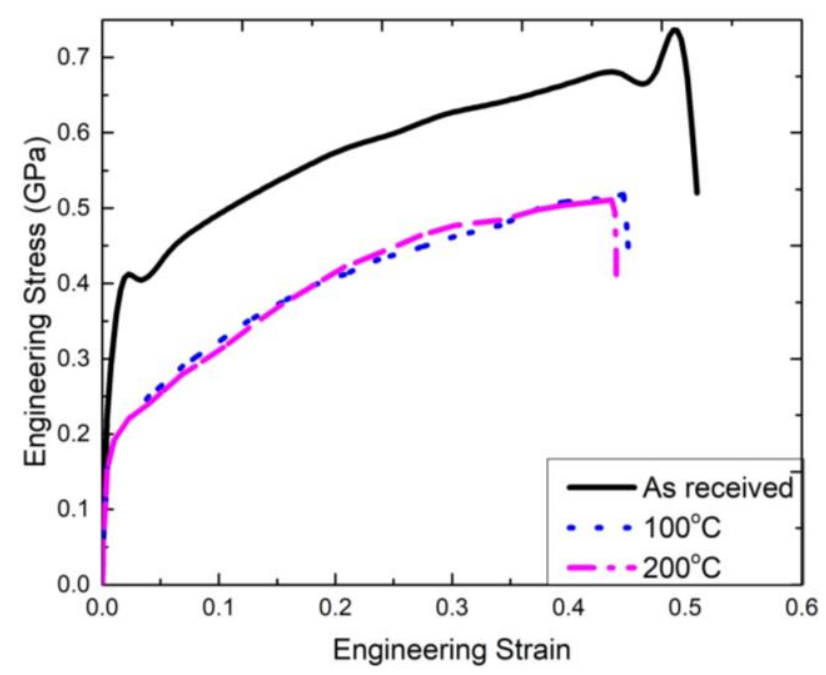

Fig. 1 Stress-strain graph of SS 304 sheet metal of $1 \mathrm{~mm}$ thickness

Table 2 Mechanical Properties of SS 304 sheets

\begin{tabular}{lccclcll}
\hline Heat treatment temperature & $\mathrm{R}_{0}$ & $\mathrm{R}_{45}$ & $\mathrm{R}_{90}$ & $\sigma_{\mathrm{y}}(\mathrm{MPa})$ & $\mathrm{E}(\mathrm{GPa})$ & $\mathrm{K}(\mathrm{MPa})$ & $\mathrm{n}$ \\
\hline As received & & & & 360 & & 1417 & 0.403 \\
$100^{\circ} \mathrm{C}$ & 1.08 & 0.96 & 1.05 & 351 & 210 & 1285 & 0.395 \\
$200^{\circ} \mathrm{C}$ & & & & 349 & & 1199 & 0.385 \\
\hline
\end{tabular}

\subsection{Experimental Design}

All the tube bulging simulations were performed based on Design of Experiments (DoE) mentioned full factorial design. Table 3 represents the considered parameters and their levels whereas Table 4 shows the full factorial experimental design with response values. Bulge ratio (BR), Thinning Ratio (TR) and Bursting Pressure (BP) were considered as the responses. The method for calculating of BR and TR can be found in the literature [32] whereas BP can be found directly from the pressure gauge and the pressure was considered just before fracture of the tubular specimen.

Table 3 Considered parameters and their levels

\begin{tabular}{cccc}
\hline Parameters & Level 1 & Level 2 & Level 3 \\
\hline A-Die Corner Radius $(\mathrm{mm})$ & 6 & 8 & 10 \\
B-Frictional coefficient $(\mathrm{CoF})$ & 0.05 & 0.08 & 0.12 \\
C-Heat Treatment Temp. $\left({ }^{\circ} \mathrm{C}\right)$ & RT & 100 & 200 \\
\hline
\end{tabular}

Table 4 Full factorial experimental design and corresponding response values

\begin{tabular}{cccccccc}
\hline StdOrder & RunOrder & A & B & C & $\begin{array}{c}\text { Bulge Ratio } \\
(\mathrm{BR})\end{array}$ & $\begin{array}{c}\text { Thinning Ratio } \\
(\mathrm{TR})\end{array}$ & $\begin{array}{c}\text { Bursting Pressure } \\
(\mathrm{BP})\end{array}$ \\
\hline
\end{tabular}




\begin{tabular}{|c|c|c|c|c|c|c|c|}
\hline 12 & 1 & 8 & 0.05 & 200 & 1.45 & 0.32 & 24.2 \\
\hline 16 & 2 & 8 & 0.12 & $\mathrm{RT}$ & 1.47 & 0.34 & 25.4 \\
\hline 9 & 3 & 6 & 0.12 & 200 & 1.45 & 0.34 & 24.1 \\
\hline 21 & 4 & 10 & 0.05 & 200 & 1.47 & 0.32 & 24.3 \\
\hline 15 & 5 & 8 & 0.08 & 200 & 1.51 & 0.39 & 24.2 \\
\hline 17 & 6 & 8 & 0.12 & 100 & 1.47 & 0.35 & 24.5 \\
\hline 13 & 7 & 8 & 0.08 & $\mathrm{RT}$ & 1.52 & 0.39 & 25.2 \\
\hline 27 & 8 & 10 & 0.12 & 200 & 1.45 & 0.30 & 24.4 \\
\hline 19 & 9 & 10 & 0.05 & RT & 1.50 & 0.33 & 25.3 \\
\hline 24 & 10 & 10 & 0.08 & 200 & 1.52 & 0.36 & 24.4 \\
\hline 1 & 11 & 6 & 0.05 & RT & 1.50 & 0.36 & 25.3 \\
\hline 4 & 12 & 6 & 0.08 & $\mathrm{RT}$ & 1.54 & 0.39 & 25.4 \\
\hline 20 & 13 & 10 & 0.05 & 100 & 1.49 & 0.33 & 24.9 \\
\hline 23 & 14 & 10 & 0.08 & 100 & 1.53 & 0.38 & 24.8 \\
\hline 7 & 15 & 6 & 0.12 & $\mathrm{RT}$ & 1.47 & 0.35 & 25.4 \\
\hline 14 & 16 & 8 & 0.08 & 100 & 1.53 & 0.41 & 24.7 \\
\hline 22 & 17 & 10 & 0.08 & $\mathrm{RT}$ & 1.53 & 0.37 & 25.3 \\
\hline 26 & 18 & 10 & 0.12 & 100 & 1.48 & 0.32 & 24.8 \\
\hline 6 & 19 & 6 & 0.08 & 200 & 1.50 & 0.39 & 24.3 \\
\hline 8 & 20 & 6 & 0.12 & 100 & 1.46 & 0.35 & 24.5 \\
\hline 5 & 21 & 6 & 0.08 & 100 & 1.52 & 0.4 & 24.7 \\
\hline 3 & 22 & 6 & 0.05 & 200 & 1.46 & 0.34 & 24.1 \\
\hline 10 & 23 & 8 & 0.05 & $\mathrm{RT}$ & 1.48 & 0.36 & 25.6 \\
\hline 2 & 24 & 6 & 0.05 & 100 & 1.50 & 0.38 & 24.9 \\
\hline 11 & 25 & 8 & 0.05 & 100 & 1.49 & 0.34 & 24.7 \\
\hline 18 & 26 & 8 & 0.12 & 200 & 1.45 & 0.31 & 24.4 \\
\hline 25 & 27 & 10 & 0.12 & $\mathrm{RT}$ & 1.47 & 0.31 & 25.5 \\
\hline
\end{tabular}

\subsection{Numerical Simulations}

Rapid advancements in the computational field during the last few decades have led the researchers to call for both numerical and analytical methods for the various mechanical design problems. Improvements in the computational field have emerged the finite element (FE) software packages and have become an essential tool for analyzing the process during the design stage. Although FE software carries out the computational part of the problems, the involvement of the users is highly essential for incorporation of the input data like boundary conditions, loading conditions, mechanical properties etc, for carrying out the simulations. So in the present case, proper care is taken to input the required data for carrying out the numerical simulations. Tools required for carrying the simulations were modelled in CATIA V5 R11. The modelled tools were saved in .igs format and imported into Pam-Stamp 2G. The L/D ratio was considered as 1 in the present study. Schematic illustration of the THF process test is exposed in fig. 2. Mechanical properties exposed in Table 2 were used for carrying out the different simulations. Except for tube, all the tools were assumed as a rigid body for carrying out numerical simulations. Die is locked for all the translational and rotational directions whereas axial plungers were given translational motion in 
the x-direction. $200 \mathrm{~mm}$ tube length and $60 \mathrm{~mm}$ diameter with $1 \mathrm{~mm}$ thickness were modelled in the analysis package itself. The tube has meshed with four-noded shell elements with a mesh size of 1. Krupowsky law and Hills 1990 yield criteria were used for performing simulations. Loading conditions for the simulations were given based on the available literature [33, 34]. Coefficient of friction values was taken from the previous works of the authors which were developed by performing pin-on-disc tests [35].

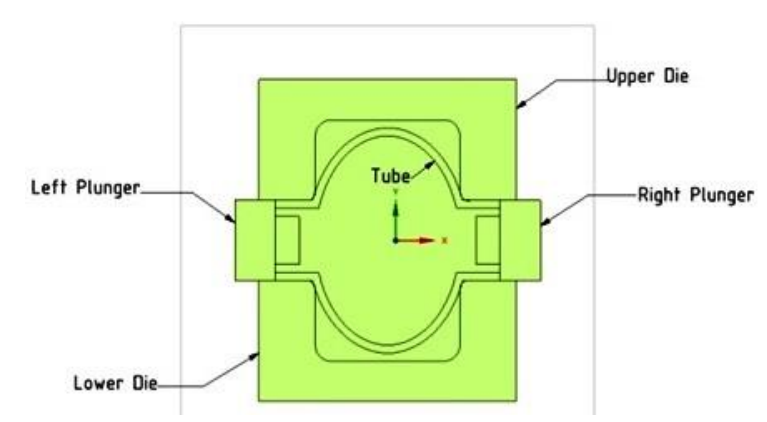

Fig. 2 Schematic illustration tube hydroforming setup

\subsection{Formulation of the decision-making problem}

Tubular hydroforming process is an unconventional forming process generally utilized in aerospace and automotive sectors for producing components which have better properties than the conventionally formed components. To keep up their performance during their actually application, they ought to have some particular properties. In those specific properties, uniform thickness distribution is one of the most significant properties. A final formed component ought to have uniform thickness all through its profile. During the THF process, most extreme thinning takes place at the corners and bulged zone because of the formation of compressive and tensile stresses. Then again, the necessary internal pressure to form the component is viewed as lower to accomplish minimum production cost. By and large, high estimations of bulge ratio (BR), low benefits of Thinning Ratio (TR) and low benefits of Bulging Pressure (BP) are required for ideal component design. Twenty-seven tests for optimal determination of the process boundaries were considered as per the full factorial design. To solve the issue, two MCDM techniques (TOPSIS and PSI) have been applied to decide the best analysis with the most desired fulfillment degree for all the models. Experimental tests offer ascent to an expansion in time and cost. In this way, in this paper, a FE model checked by experimentation results has been utilized for conducting the parametric examination.

\subsubsection{Weight Measurement using ENTROPY method}

In the current work, Entropy technique was employed to weight the entire criterion to attain more practical weight coefficients. Entropy scheme was developed by Shannon with a thought of thermodynamics [36]. The important steps in entropy scheme are the normalization and calculating the entropy values and their weights [37]. The decision matrix of an MCDM problem is shown in 
Eq. $1, X_{i j}(i=1 \ldots \ldots, m ; j=1 \ldots \ldots, n)$ shows the arrangement consequence of the $i^{\text {th }}$ alternative to the $\mathrm{j}^{\text {th }}$ condition. From the entropy technique, it is understandable that characteristics with prominent entropy have a prominent variety of output limitations. This characteristic has highest significant consequence of the output response.

The representation of the decision matrix $D_{m \times n}$ is shown in equation 1 .

$$
D_{m \times n}=\left[\begin{array}{ccc}
\mathrm{X}_{11} & \cdots & \mathrm{X}_{1 \mathrm{n}} \\
\vdots & \ddots & \vdots \\
\mathrm{X}_{\mathrm{m} 1} & \cdots & \mathrm{X}_{\mathrm{mn}}
\end{array}\right]
$$

$D_{m \times n}$ is normalized with the help of equation 2

$$
N_{i j}=\frac{\mathrm{x}_{\mathrm{ij}}}{\sqrt{\sum \mathrm{x}_{\mathrm{ij}}^{2}}} \text { for } \mathrm{i}=1, \mathrm{~m}: \mathrm{j}=1 \ldots \ldots \mathrm{n}
$$

Thus, $W_{e}(X)$ are employed as a mapping function for entropy calculation; and is represented equation 3.

$$
W_{e}(X)=X e^{1}-X+(1-X) e^{X}-1
$$

The maximum value of the above function can be found at $\mathrm{x}=0.5$ and the value of $e^{0.5}-1=$ 0.6487 . The mapping consequence can be arranged within a range of $[0,1]$, and the updated entropy is measured as

$$
\mathrm{W}=\frac{1}{\mathrm{e}^{0.5-1}} \sum_{\mathrm{i}=1}^{\mathrm{m}} \mathrm{w}_{\mathrm{e}}(\mathrm{X})
$$

The entire normalized matrix is added for the whole progression with the help equation 5.

$$
D_{k}=\sum_{\mathrm{i}=1}^{\mathrm{m}} \gamma_{\mathrm{i}}(\mathrm{k})(\mathrm{k}=1 \ldots \ldots \ldots \mathrm{n})
$$

Coefficients of normalized matrix are measured by using equation 6 .

$$
\mathrm{C}=\frac{1}{\mathrm{e}^{(0.5-1) * \mathrm{~m}}}=\frac{1}{0.06487 * \mathrm{~m}}
$$

Entropy value of each goal is anticipated by equation 7

$$
\mathrm{e}_{\mathrm{k}}=\mathrm{C} \sum_{\mathrm{i}=1}^{\mathrm{m}} \mathrm{w}_{\mathrm{e}}\left(\frac{\gamma_{\mathrm{i}}(\mathrm{k})}{\mathrm{D}_{\mathrm{k}}}\right)
$$


All the entropy values is added by equation 8

$$
\mathrm{E}=\sum_{\mathrm{k}=1}^{\mathrm{n}} \mathrm{e}_{\mathrm{k}}
$$

Weight of each objective is obtained as

$$
\mathrm{W}_{\mathrm{k}}=\frac{\frac{1}{(\mathrm{n}-\mathrm{E})}\left(1-\mathrm{e}_{\mathrm{k}}\right)}{\sum_{\mathrm{k}=1}^{\mathrm{n}} \frac{1}{(\mathrm{n}-\mathrm{E})}\left(1-\mathrm{e}_{\mathrm{k}}\right)}
$$

In the current research work, $m$ is 27 and $n$ is 3 . The measured entropy values of BR, TR and BP are $0.99994,0.99890$ and 0.99994 and their weights are $0.0444,0.9099$ and 0.0456 respectively.

\subsubsection{TOPSIS method}

TOPSIS technique was introduced in the year 1980 by Yoon and Hwang which is developed on the thought that the best alternative would have a shortest distance from the best outcome. The procedure for TOPSIS implementing are summarized below [38, 39]:

$1^{\text {st }}$ Step: Development of normalized $D_{k}$ as represented in Eq. 1.

$2^{\text {nd }}$ Step: Development of the weighted normalized $T_{i j}$. The normalized $D_{k}$ is multiplied by their corresponding weights $\left(W_{j}\right)$ and is defined as:

$$
T_{i j}=D_{k} * W_{j}
$$

$\mathrm{i}=1 \ldots . . \mathrm{m} ; \mathrm{j}=1 \ldots \mathrm{n}$

$3^{\text {rd }}$ Step: The ideal and negative ideal solutions are determined respectively, as follows:

$$
\begin{aligned}
& \left\{T_{1}^{+}, T_{2}^{+}, \ldots \ldots . T_{n}^{+}\right\}=\left\{\left(\left(\operatorname{Max}_{i} T_{i j} \mid j \in K\right),\left(\operatorname{Min}_{i} T_{i j} \mid j \in K^{\prime}\right) \mid i=1,2 \ldots \ldots, m\right)\right\} \\
& \left\{T_{1}^{-}, T_{2}^{-}, \ldots \ldots . T_{n}^{-}\right\}=\left\{\left(\left(\operatorname{Min}_{i} T_{i j} \mid j \in K\right),\left(\operatorname{Max}_{i j} \mid j \in K^{\prime}\right) \mid i=1,2 \ldots \ldots, m\right)\right\}
\end{aligned}
$$

$K$ is considered as the benefit criteria index and $K^{\prime}$ is non-benefit criteria index.

$4^{\text {th }}$ Step: Evaluating the distances from the ideal solution and negative ideal solutions by equations 13 and 14

$$
\begin{gathered}
S_{i}^{+}=\left\{\sum_{j=1}^{n}\left(T_{i j}-T_{j}^{+}\right)^{2}\right\}^{0.5} \quad \mathrm{i}=1 \ldots \ldots \mathrm{m} ; \mathrm{j}=1 \ldots \mathrm{n} \\
S_{i}^{-}=\left\{\sum_{j=1}^{n}\left(T_{i j}-T_{j}^{-}\right)^{2}\right\}^{0.5} \quad \mathrm{i}=1 \ldots . . \mathrm{m} ; \mathrm{j}=1 \ldots \mathrm{n}
\end{gathered}
$$


$5^{\text {th }}$ Step: Evaluation of the relative closeness with ideal solution. The proportional nearness of an alternative to the ideal solution is measured by equation 15 and the best alternative is mentioned with highest $\mathrm{A}_{\mathrm{i}}$ :

$$
A_{i}=\frac{S_{i}^{-}}{S_{i}^{+}+S_{i}^{-}} \quad \mathrm{i}=1 \ldots \ldots \mathrm{m} ; 0 \leq A_{i} \leq 1
$$

\subsubsection{PSI METHOD}

Maniya and Bhatt in the year 2010 have developed this PSI method for providing solutions for MCDM problems, especially in material selection [28]. Unlike the other MCDM schemes, PSI do not require weight criteria for the determination of relative importance. Thus, the method is very helpful where there is a deciding conflict for the comparative significance between the criteria. PSI establishes the criterion weights based on decision matrix information, i.e., it is similar to standard deviation or entropy method. Application of the PSI for solving MCDM problems possesses various steps $[28,40]$.

$1^{\text {st }}$ Step: Determination of purpose and detection of the appropriate criterion for the evaluation of the alternatives.

$2^{\text {nd }}$ Step: Initial decision matrix, $D_{m \times n}$ as shown in equation 1 :

$$
D_{m \times n}=\left[X_{i j}\right]_{\mathrm{mxn}}=\left[\begin{array}{ccc}
\mathrm{X}_{11} & \cdots & \mathrm{X}_{1 \mathrm{n}} \\
\vdots & \ddots & \vdots \\
\mathrm{X}_{\mathrm{m} 1} & \cdots & \mathrm{X}_{\mathrm{mn}}
\end{array}\right]
$$

$3^{\text {rd }}$ Step: Normalization of decision matrix using equations 16 and 17:

for maximization (beneficial) criteria:

$$
\bar{x}_{\mathrm{ij}}=\frac{x_{i j}}{x_{i j}^{\text {max }}}, \mathrm{i}=1, \ldots \ldots . \mathrm{m}
$$

for minimization (non-beneficial) criteria:

$$
\bar{x}_{\mathrm{ij}}=\frac{x_{i j}^{\min }}{x_{i j}}, \mathrm{i}=1, \ldots \ldots, \mathrm{m}
$$

$4^{\text {th }}$ Step: Mean values determination for normalized performances by equation 18 :

$$
\mathrm{N}=\frac{1}{n} \sum_{i=1}^{m} \bar{x}_{\mathrm{ij}}
$$

$5^{\text {th }}$ Step: Evaluation of the preferences variation by equation 19 :

$$
\varphi_{j}=\sum_{i=1}^{m}\left(\bar{x}_{i j}-N\right)^{2}
$$

$6^{\text {th }}$ Step: Evaluation of the deviations value for the preferences by equation 20 :

$$
\Omega_{j}=1-\varphi_{j}
$$


$7^{\text {th }}$ Step: Evaluation of criterion weights using equation 21:

$$
w_{j}=\frac{\Omega_{j}}{\sum_{j=1}^{n} \Omega_{j}}
$$

$8^{\text {th }}$ Step: Evaluation of the PSI of alternatives by equation 22:

$$
\theta_{i}=\sum_{j=1}^{n} \bar{x}_{i j} w_{j}
$$

\section{Results and discussion}

To exhibit the applicability of TOPSIS method in conjunction with the entropy weighting method and PSI method, THF process parameters selection was measured. The application procedure for Entropy, TOPSIS and PSI methods were discussed in previous sections. After the determination of the weights by Entropy method, the TOPSIS and PSI MCDM methods were applied to the problem. The decision model for the THF process parametric selection problem is shown in fig. 3.

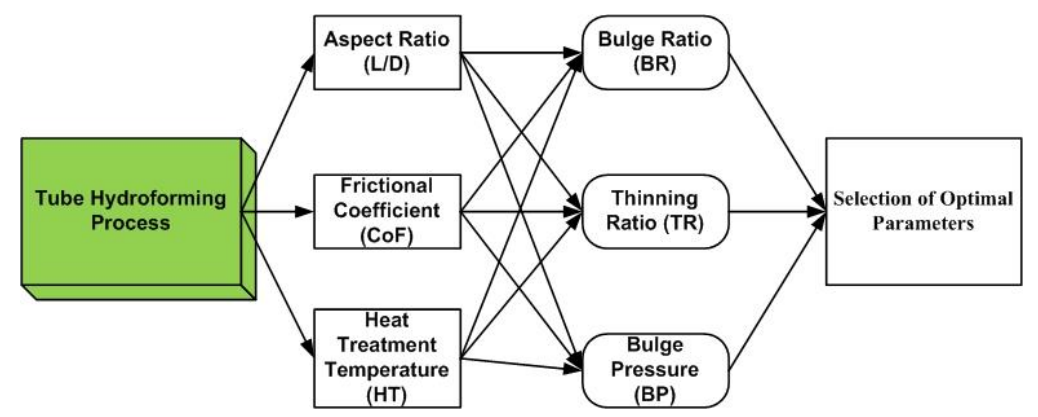

Fig. 3 Decision model for Tube hydroforming process

\subsection{Application of the TOPSIS method}

To obtain optimized multiple performance characteristics, TOPSIS approach was not practiced directly in the present study. Since the contribution of each performance characteristic may not have a similar influence. With a specific end goal to find the relative impact of every performance criterion a statistical procedure called entropy method has been employed to determine the weighting percentage of every performance parameter.

Table 5 represents the weighted normalized decision matrix $\left(T_{i j}\right)$. The ideal solution and negative ideal solutions were obtained by equations 11 and 12, and is shown in Table 6. Distances from the ideal solution $\left(\mathrm{Si}^{+}\right)$and negative ideal solution $\left(\mathrm{Si}^{-}\right)$are represented in Table 7, the comparative closeness to the ideal solution $\left(A_{i}\right)$ calculated by equations (13-15). Finally the ranks of each alternative were found out. It is observed that the best and the worst combinations were experiments \#8 and \#16, respectively.

Table 5 Weighted and normalized decision matrix $\left(\mathrm{V}_{\mathrm{ij}}\right)$

\begin{tabular}{cccc}
\hline S. No & BR & TR & BP \\
\hline 1 & 0.008328 & 0.158187 & 0.008573 \\
\hline
\end{tabular}




\begin{tabular}{rrrr}
\hline 2 & 0.008443 & 0.168074 & 0.008998 \\
3 & 0.008328 & 0.168074 & 0.008537 \\
4 & 0.008443 & 0.158187 & 0.008608 \\
5 & 0.008672 & 0.19279 & 0.008573 \\
6 & 0.008443 & 0.173017 & 0.008679 \\
7 & 0.00873 & 0.19279 & 0.008927 \\
8 & 0.008328 & 0.1483 & 0.008644 \\
9 & 0.008615 & 0.16313 & 0.008963 \\
10 & 0.00873 & 0.17796 & 0.008644 \\
11 & 0.008615 & 0.17796 & 0.008963 \\
12 & 0.008845 & 0.19279 & 0.008998 \\
13 & 0.008557 & 0.16313 & 0.008821 \\
14 & 0.008787 & 0.187847 & 0.008785 \\
15 & 0.008443 & 0.173017 & 0.008998 \\
16 & 0.008787 & 0.202677 & 0.00875 \\
17 & 0.008787 & 0.182904 & 0.008963 \\
18 & 0.0085 & 0.158187 & 0.008785 \\
19 & 0.008615 & 0.19279 & 0.008608 \\
20 & 0.008385 & 0.173017 & 0.008679 \\
21 & 0.00873 & 0.197734 & 0.00875 \\
22 & 0.008385 & 0.168074 & 0.008537 \\
23 & 0.0085 & 0.17796 & 0.009069 \\
24 & 0.008615 & 0.187847 & 0.008821 \\
25 & 0.008557 & 0.168074 & 0.00875 \\
26 & 0.008328 & 0.153244 & 0.008644 \\
27 & 0.008443 & 0.153244 & 0.009033 \\
\hline
\end{tabular}

Table 6 The ideal and negative ideal solutions

\begin{tabular}{cccc}
\hline & BR & TR & BP \\
\hline $\mathrm{V}^{+}$ & 0.008845 & 0.1483 & 0.008537 \\
$\mathrm{~V}^{-}$ & 0.008328 & 0.202677 & 0.009069 \\
\hline
\end{tabular}

Table $7 \mathrm{Si}^{+}$, $\mathrm{Si}^{-}$and $\mathrm{C}_{\mathrm{i}}$

\begin{tabular}{crrrr}
\hline S. No & \multicolumn{1}{c}{$\mathrm{Si}^{+}$} & $\mathrm{Si}^{-}$ & \multicolumn{1}{c}{$\mathrm{C}_{\mathrm{i}}$} & Ranking \\
\hline 1 & 0.0099 & 0.044493 & 0.817987 & 6 \\
2 & 0.019783 & 0.034604 & 0.636255 & 12 \\
3 & 0.01978 & 0.034607 & 0.636312 & 11 \\
4 & 0.009895 & 0.044493 & 0.818064 & 4 \\
5 & 0.04449 & 0.009905 & 0.182094 & 22 \\
6 & 0.02472 & 0.029663 & 0.545441 & 13 \\
7 & 0.044492 & 0.009896 & 0.18195 & 25 \\
8 & 0.000528 & 0.054378 & 0.990389 & 1 \\
9 & 0.014838 & 0.039548 & 0.727173 & 8 \\
10 & 0.02966 & 0.024724 & 0.454611 & 16 \\
\hline
\end{tabular}




\begin{tabular}{rrrrr}
\hline 11 & 0.029664 & 0.024719 & 0.454532 & 17 \\
12 & 0.044492 & 0.0099 & 0.182017 & 24 \\
13 & 0.014836 & 0.039548 & 0.727207 & 7 \\
14 & 0.039548 & 0.01484 & 0.272855 & 20 \\
15 & 0.024724 & 0.02966 & 0.545381 & 15 \\
16 & 0.054377 & 0.000559 & 0.01018 & 27 \\
17 & 0.034606 & 0.019779 & 0.363684 & 19 \\
18 & 0.009896 & 0.044491 & 0.818049 & 5 \\
19 & 0.044491 & 0.009902 & 0.18204 & 23 \\
20 & 0.024721 & 0.029663 & 0.54543 & 14 \\
21 & 0.049434 & 0.00497 & 0.091352 & 26 \\
22 & 0.019779 & 0.034608 & 0.636329 & 10 \\
23 & 0.029667 & 0.024717 & 0.454495 & 18 \\
24 & 0.039548 & 0.014835 & 0.272784 & 21 \\
25 & 0.019777 & 0.034606 & 0.636341 & 9 \\
26 & 0.004971 & 0.049435 & 0.908625 & 2 \\
27 & 0.004984 & 0.049434 & 0.908405 & 3 \\
\hline
\end{tabular}

Optimization of THF process with numerous attributes like BR, TR and BP was executed using the TOPSIS method. The results obtained by conducting the simulations, the preference values for each combination were accomplished by equations (10-14). The preference values of each combination were designed by considering its relative nearness to the most excellent solution. All the output responses are multiplied based on entropy weightage criteria. The preference values based on TOPSIS approach for each test conditions along with the ranks are tabulated in Table 7. The comparative closeness to best solution concerning the optimal presentation compute attains the utmost preference significance and is allotted as the best rank and considers as the improved value for the performance measure. It is observed that test run \#8 is having the most excellent compound performance characteristics having the maximum preference order; hence it is considered as the optimal setting followed by \#26 and \#27 runs. The optimal setting obtained is a corner radius of $10 \mathrm{~mm}$, frictional coefficient of 0.12 and a heat treatment temperature of $200^{\circ} \mathrm{C}$.

\subsection{Application of the PSI method}

The total evaluation process of the PSI technique for solving the aforementioned parameter selection for THF process, MCDM problem is pursued. The decision matrix for THF process is already given in equation 1, the relevance of the PSI method started by using equations 16 and 17. By using these two equations, the normalized decision matrix is attained and represented in Table 8. The purpose of normalization is to attain dimensionless values of different characteristic standards such that the choices can be easily processed.

Table 8 Values of the variation of preferences using PSI

Normalized $\quad$ Variation of Preferences $\quad$ PSI




\begin{tabular}{|c|c|c|c|c|c|c|c|c|}
\hline $\begin{array}{l}\mathrm{S} . \\
\mathrm{N}\end{array}$ & BR & TR & $\overline{\mathrm{BP}}$ & $\overline{\mathrm{BR}}$ & TR & $\mathrm{BP}$ & & $\begin{array}{c}\text { Ranking } \\
\mathrm{s}\end{array}$ \\
\hline $\begin{array}{l}0 \\
1\end{array}$ & $\begin{array}{c}0.94155 \\
8\end{array}$ & 0.9375 & $\begin{array}{c}0.99586 \\
8\end{array}$ & $\begin{array}{c}0.38341 \\
9\end{array}$ & $\begin{array}{c}0.42526 \\
7\end{array}$ & $\begin{array}{c}0.45115 \\
5\end{array}$ & $\begin{array}{c}0.96014 \\
9\end{array}$ & 4 \\
\hline 2 & 0.95454 & 0.88235 & 0.94881 & 0.39967 & 0.35638 & 0.39016 & 0.93237 & \\
\hline & 5 & 3 & 9 & 1 & 3 & 5 & 7 & 15 \\
\hline 3 & $\begin{array}{c}0.94155 \\
8\end{array}$ & $\begin{array}{c}0.88235 \\
3\end{array}$ & 1 & $\begin{array}{c}0.38341 \\
9\end{array}$ & $\begin{array}{c}0.35638 \\
3\end{array}$ & $\begin{array}{c}0.45672 \\
3\end{array}$ & $\begin{array}{c}0.94630 \\
4\end{array}$ & 11 \\
\hline 4 & $\begin{array}{c}0.95454 \\
5\end{array}$ & 0.9375 & 0.99177 & $\begin{array}{c}0.39967 \\
1\end{array}$ & $\begin{array}{c}0.42526 \\
7\end{array}$ & $\begin{array}{c}0.44566 \\
6\end{array}$ & $\begin{array}{c}0.96331 \\
8\end{array}$ & 3 \\
\hline 5 & $\begin{array}{c}0.98051 \\
9\end{array}$ & $\begin{array}{c}0.76923 \\
1\end{array}$ & $\begin{array}{c}0.99586 \\
8\end{array}$ & $\begin{array}{c}0.43318 \\
7\end{array}$ & $\begin{array}{c}0.23411 \\
6\end{array}$ & $\begin{array}{c}0.45115 \\
5\end{array}$ & $\begin{array}{c}0.92729 \\
8\end{array}$ & 18 \\
\hline 6 & $\begin{array}{c}0.95454 \\
5\end{array}$ & $\begin{array}{c}0.85714 \\
3\end{array}$ & $\begin{array}{c}0.98367 \\
3\end{array}$ & $\begin{array}{c}0.39967 \\
1\end{array}$ & $\begin{array}{c}0.32691 \\
8\end{array}$ & $\begin{array}{c}0.43492 \\
2\end{array}$ & $\begin{array}{c}0.93801 \\
8\end{array}$ & 13 \\
\hline 7 & $\begin{array}{c}0.98701 \\
3\end{array}$ & $\begin{array}{c}0.76923 \\
1\end{array}$ & $\begin{array}{c}0.95634 \\
9\end{array}$ & $\begin{array}{c}0.44177 \\
7\end{array}$ & $\begin{array}{c}0.23411 \\
6\end{array}$ & $\begin{array}{c}0.39962 \\
9\end{array}$ & $\begin{array}{c}0.91527 \\
7\end{array}$ & 26 \\
\hline 8 & $\begin{array}{c}0.94155 \\
8\end{array}$ & 1 & $\begin{array}{c}0.98770 \\
5\end{array}$ & $\begin{array}{c}0.38341 \\
9\end{array}$ & $\begin{array}{c}0.51068 \\
9\end{array}$ & $\begin{array}{c}0.44025 \\
6\end{array}$ & $\begin{array}{c}0.97457 \\
6\end{array}$ & 1 \\
\hline 9 & $\begin{array}{c}0.97402 \\
6\end{array}$ & $\begin{array}{c}0.90909 \\
1\end{array}$ & $\begin{array}{c}0.95256 \\
9\end{array}$ & $\begin{array}{c}0.42468 \\
2\end{array}$ & $\begin{array}{c}0.38902 \\
2\end{array}$ & $\begin{array}{c}0.39486 \\
4\end{array}$ & $\begin{array}{c}0.94816 \\
5\end{array}$ & 9 \\
\hline 10 & 0.98701 & 0.83333 & 0.98770 & 0.44177 & 0.30025 & 0.44025 & 00445 & 12 \\
\hline 11 & 0.97402 & 0.83333 & 0.95256 & 0.42468 & 0.30025 & 0.39486 & 0.92708 & \\
\hline 12 & $\begin{array}{l}6 \\
1\end{array}$ & $\begin{array}{c}3 \\
0.769\end{array}$ & $\begin{array}{c}9 \\
48\end{array}$ & 2 & $\begin{array}{c}8 \\
23411\end{array}$ & $\begin{array}{c}4 \\
39016\end{array}$ & 4 & 19 \\
\hline & & 1 & $\begin{array}{c}7+0 \\
9\end{array}$ & 0.45921 & 6 & 5 & 0.9172 & 24 \\
\hline 13 & $\begin{array}{c}0.96753 \\
2\end{array}$ & $\begin{array}{c}0.90909 \\
1\end{array}$ & $\begin{array}{c}0.96787 \\
1\end{array}$ & 0.41626 & $\begin{array}{c}0.38902 \\
2\end{array}$ & 0.41433 & $\begin{array}{c}0.95139 \\
3\end{array}$ & 7 \\
\hline 14 & $\begin{array}{c}0.99350 \\
6\end{array}$ & $\begin{array}{c}0.78947 \\
4\end{array}$ & $\begin{array}{c}0.97177 \\
4\end{array}$ & $\begin{array}{c}0.45045 \\
1\end{array}$ & $\begin{array}{c}0.25411 \\
5\end{array}$ & $\begin{array}{c}0.41936 \\
9\end{array}$ & 0.92884 & 16 \\
\hline 15 & 0.95454 & 0.85714 & $\begin{array}{c}0.94881 \\
0\end{array}$ & 0.39967 & $\begin{array}{c}0.32691 \\
8\end{array}$ & 0.39016 & 0.92536 & \\
\hline 16 & 0.99350 & 0.73170 & 0.97570 & 0.45045 & 0.19921 & & 0.91419 & \\
\hline & 6 & 7 & 9 & 1 & 3 & 0.42448 & 4 & 27 \\
\hline 17 & $\begin{array}{c}0.99350 \\
6\end{array}$ & $\begin{array}{c}0.81081 \\
1\end{array}$ & $\begin{array}{c}0.95256 \\
9\end{array}$ & $\begin{array}{c}0.45045 \\
1\end{array}$ & $\begin{array}{c}0.27608 \\
3\end{array}$ & $\begin{array}{c}0.39486 \\
4\end{array}$ & $\begin{array}{c}0.92780 \\
3\end{array}$ & 17 \\
\hline 18 & $\begin{array}{c}0.96103 \\
9\end{array}$ & 0.9375 & $\begin{array}{c}0.97177 \\
4\end{array}$ & $\begin{array}{c}0.40792 \\
4\end{array}$ & $\begin{array}{c}0.42526 \\
7\end{array}$ & $\begin{array}{c}0.41936 \\
9\end{array}$ & $\begin{array}{c}0.95838 \\
6\end{array}$ & 5 \\
\hline 19 & $\begin{array}{c}0.97402 \\
6\end{array}$ & $\begin{array}{c}0.76923 \\
1\end{array}$ & 0.99177 & $\begin{array}{c}0.42468 \\
2\end{array}$ & $\begin{array}{c}0.23411 \\
6\end{array}$ & $\begin{array}{c}0.44566 \\
6\end{array}$ & $\begin{array}{c}0.92348 \\
2\end{array}$ & 21 \\
\hline 20 & 0.94805 & 0.85714 & 0.98367 & 0.39150 & 0.32691 & 0.43492 & & \\
\hline 21 & $\begin{array}{c}0.98701 \\
3\end{array}$ & 0.75 & $\begin{array}{c}0.97570 \\
9\end{array}$ & $\begin{array}{c}0.44177 \\
7\end{array}$ & $\begin{array}{c}0.21587 \\
6\end{array}$ & 0.42448 & $\begin{array}{c}0.91695 \\
6\end{array}$ & 25 \\
\hline
\end{tabular}




\begin{tabular}{ccccccccc}
\hline 22 & 0.94805 & 0.88235 & 1 & 0.39150 & 0.35638 & 0.45672 & 0.94863 & \\
& 2 & 3 & & 3 & 3 & 3 & 3 & 8 \\
23 & 0.96103 & 0.83333 & 0.94140 & 0.40792 & 0.30025 & & 0.91837 & \\
& 9 & 3 & 6 & 4 & 8 & 0.38096 & 3 & 23 \\
24 & 0.97402 & 0.78947 & 0.96787 & 0.42468 & 0.25411 & & 0.92043 & \\
& 6 & 4 & 1 & 2 & 5 & 0.41433 & 6 & 22 \\
25 & 0.96753 & 0.88235 & 0.97570 & & 0.35638 & & 0.94679 & \\
& 2 & 3 & 9 & 0.41626 & 3 & 0.42448 & 8 & 10 \\
26 & 0.94155 & 0.96774 & 0.98770 & 0.38341 & 0.46562 & 0.44025 & & \\
& 8 & 2 & 5 & 9 & 5 & 6 & 0.9656 & 2 \\
27 & 0.95454 & 0.96774 & 0.94509 & 0.39967 & 0.46562 & 0.38553 & 0.95478 & \\
& 5 & 2 & 8 & 1 & 5 & 1 & 6 & 6 \\
\hline
\end{tabular}

Using the normalized data, by using equation 18, average values of normalized presentations with respect to every measure are acquired as $\mathrm{N}=[0.3223,0.2853,0.3241]$. Consequently, by about equation 19, a variation of preference values about every standard is calculated.

By utilizing equation 20, variations of the preference value in connection to every condition are obtained. Consequently, by equation 21 , weights criterion are calculated as $\mathrm{W}=[0.3586,0.2782$, 0.3631]. Finally, employing equation 22, PSI of each test runs are determined by which whole rankings of choices are obtained and represented in Table 8.

\subsection{Comparison of MCDM techniques}

THF parameters selection ranking by both the MCDM techniques is illustrated in Fig. 4. It is observed that experiment number \#8 has the best rank for both the TOPSIS and PSI techniques. Moreover, experiment number \#16 has the worst rank in the two methods. From this result, it is concluded that both the MCDM methods attained the same best and worst ranks. Rankings between first and last were different for the two methods.

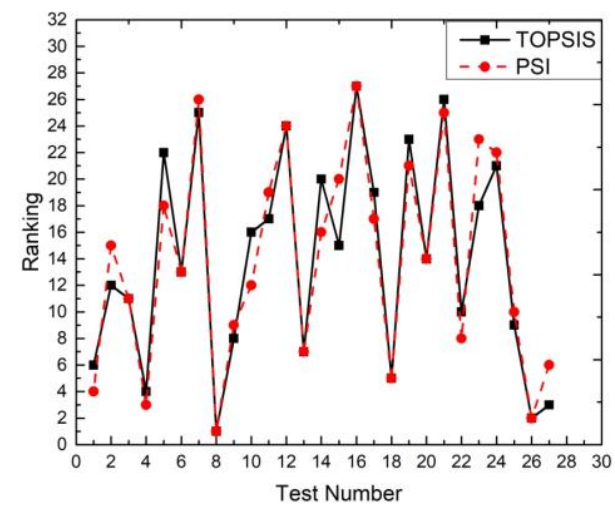

Fig. 4 Rankings of two MCDM methods for various tests 


\subsection{THF experiments on SS 304 tubes}

All experimentations were conducted at the author's institute located in INDIA. The experimental test setup is fabricated at the institute and is shown in fig. 5 (a). The fabricated test setup can generate an internal pressure up to $50 \mathrm{MPa}$ and has an axial cylinder pressure up to a load of 50 $\mathrm{kN} / \mathrm{m}^{2}$. The tubes were prepared to a length of $200 \mathrm{~mm}$ since the simulations were performed with the same length. The tubes were heat-treated to a temperature of $200^{\circ} \mathrm{C}$ in a muffle furnace as shown in fig. 5 (b). The dies were fabricated with a corner radius of $10 \mathrm{~mm}$ as the best product obtained with such corner radii. Before keeping the tube specimens into the die cavity, proper lubrication was applied over the die and tube surface. After inserting the tube into the die cavity, the loading of fluid into the tube is pumped using a hydraulic pump. Once the tube starts bulging, axial cylinders valve was opened to create axial force and the tube gets bulged, the pressure was examined through a pressure gauge. Bulged specimens were inspected for defects like buckling; wrinkling and bursting and also its surface quality was inspected. Finally, bulged tube height, tube wall thickness distribution and internal pressure measurements were studied. The experimental and simulated bulged specimen with test condition \#8 is shown in fig. 6 (a \& b) respectively. If the die corner radius is lower and sharp then the tube leads to necking thereby occurrence of cracks will be observed usually.

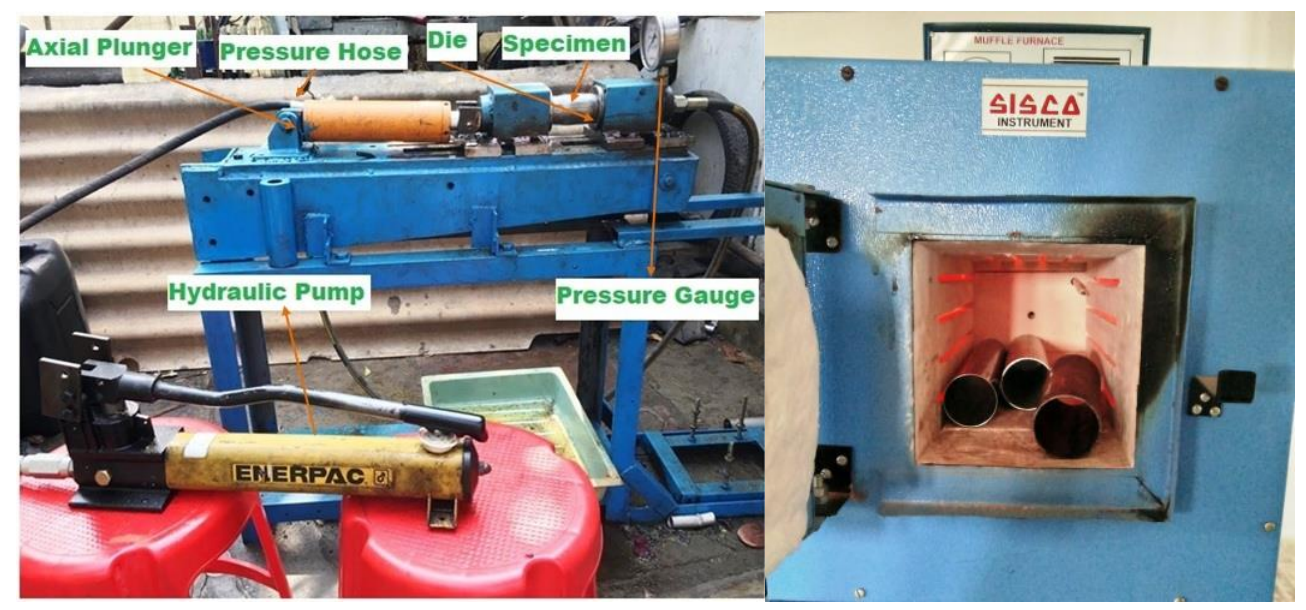

Fig. 5 Tube hydroforming a) Experimental Test setup and b) Heat treating of tubes in Muffle furnace 

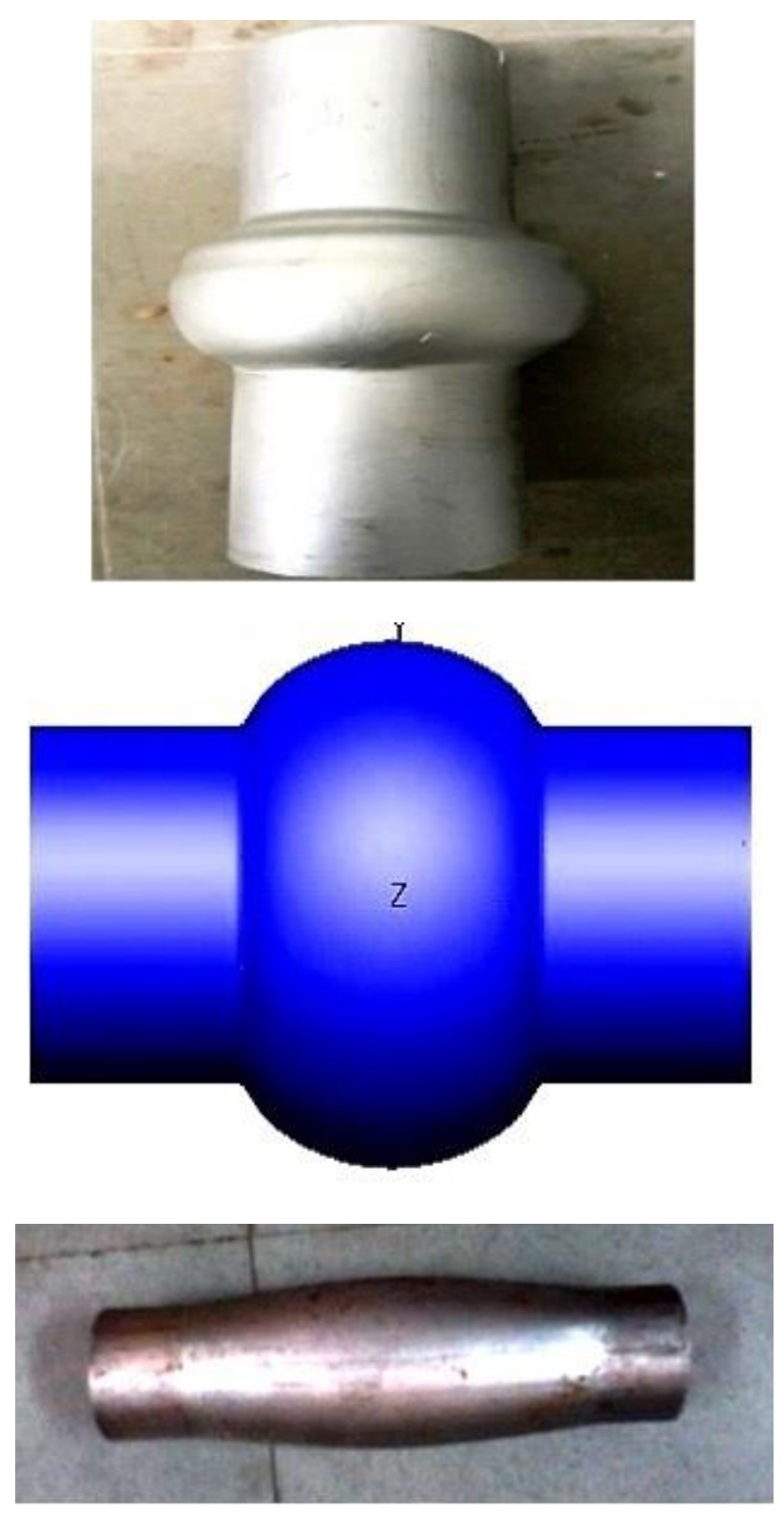

Fig. 6 Hydroformed samples a) experimentally formed sample, b) simulated formed sample, c) intermittent forming tubular sample

\subsection{Statistical Analysis}

\subsubsection{ANOVA of Bulge Ratio}

Table 9 shows the ANOVA table of bulge ratio. From the Table 9, it is evident that the friction coefficient (B) and heat treatment temperature (C) are statistically significant on the bulge ratio, whereas die corner radius (A) is not significant. The percentage contribution of factor $\mathrm{B}$ and $\mathrm{C}$ is observed to be $81.4 \%$ and $17.1 \%$ respectively. The contour plot of bulge ratio concerning two statistically significant factors $\mathrm{B}$ and $\mathrm{C}$ is shown in fig. 7. From the fig. 7, clear illustration with two factor effects can be found for obtaining a higher bulge ratio. From the fig. 7 , one can draw 
the limits of the factors that yield a better response result. In the present case, the limits for factor $\mathrm{B}$ and $\mathrm{C}$ is found to be $0.065-0.095$ and $0-150$ respectively.

Table 9 ANOVA of the Bulge ratio

\begin{tabular}{lrrrrrr}
\hline Source & DF & \multicolumn{1}{c}{ Adj SS } & Adj MS & F-Value & P-Value & \% Contribution \\
\hline A & 2 & 0.000274 & 0.000137 & 2.27 & 0.129 & 1.37 \\
B & 2 & 0.016274 & 0.008137 & 134.79 & 0 & 81.46 \\
C & 2 & 0.00343 & 0.001715 & 28.4 & 0 & 17.16 \\
Error & 20 & 0.001207 & 0.00006 & & & \\
Total & 26 & 0.021185 & & & & \\
& & & Model Summary & & \\
S & R-sq & R-sq(adj) & R-sq(pred) & & & \\
$\mathbf{0 . 0 0 7 7 7}$ & $94.30 \%$ & $92.59 \%$ & $89.61 \%$ & & & \\
\hline
\end{tabular}

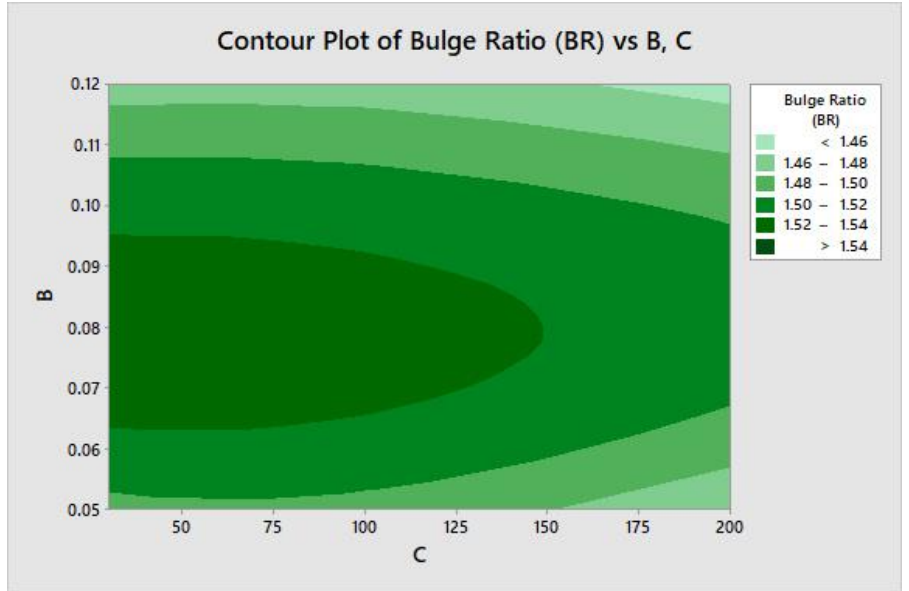

Fig. 7 Contour image of Bulge ratio against two significant factors frictional coefficient and heat treatment temperature

\subsubsection{ANOVA of Thinning Ratio}

Table 10 shows the ANOVA table of thinning ratio. From the Table 10, it is evident that the die corner radius (A) and friction coefficient (B) are statistically significant on the thinning ratio, whereas heat treatment temperature $(\mathrm{C})$ is not affected much on the response. Factors $\mathrm{A}$ and $\mathrm{B}$ contribute $20.05 \%$ and $70.6 \%$ respectively. The contour plot of thinning ratio concerning two statistically significant factors $\mathrm{A}$ and $\mathrm{B}$ is shown in fig. 8. From the fig. 8, clear illustration with two factor effects can be found for obtaining a lower thinning ratio. From the fig. 8, one can draw the limits of the factors that yield a better response result. In the present case, the limits for factor $\mathrm{A}$ and $\mathrm{B}$ is found to be 9.5-10 and 0.115-0.12 respectively.

Table 10 ANOVA of the Thinning ratio 


\begin{tabular}{|c|c|c|c|c|c|c|}
\hline Source & DF & Adj SS & Adj MS & F-Value & P-Value & \% Contribution \\
\hline$\overline{\mathbf{A}}$ & 2 & 0.004541 & 0.00227 & 26.42 & $\overline{0}$ & 20.05 \\
\hline B & 2 & 0.016007 & 0.008004 & 93.15 & 0 & 70.69 \\
\hline $\mathrm{C}$ & 2 & 0.002096 & 0.001048 & 12.2 & 0 & 9.25 \\
\hline Error & 20 & 0.001719 & 0.000086 & & & \\
\hline Total & 26 & 0.024363 & & & & \\
\hline \multicolumn{7}{|c|}{ Model Summary } \\
\hline $\mathbf{S}$ & R-sq & R-sq(adj) & R-sq(pred) & & & \\
\hline 0.00927 & $92.95 \%$ & $90.83 \%$ & $87.14 \%$ & & & \\
\hline
\end{tabular}

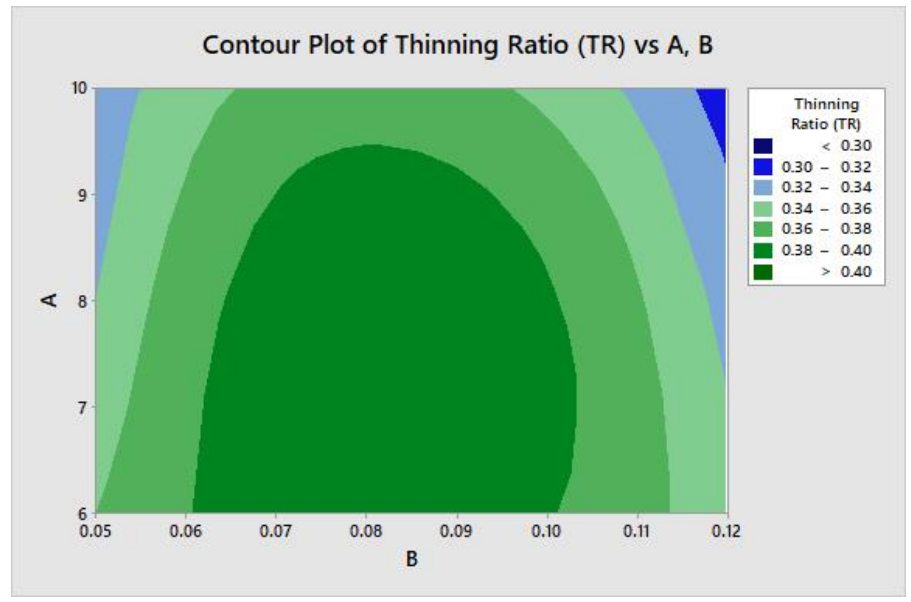

Fig. 8 Contour image of thinning ratio against two significant factors corner radius and frictional coefficient

\subsubsection{ANOVA of Bursting Pressure}

Table 11 shows the ANOVA table of bursting pressure. From the Table 11, it is evident that the heat treatment temperature (C) is the only factor which is statistically significant on the thinning ratio, whereas die corner radius (A) and friction coefficient (B) are not affected much on the response. The percentage contribution of factor $\mathrm{A}, \mathrm{B}$ and $\mathrm{C}$ is observed to be $1.01 \%, 0.11 \%$ and $98.78 \%$ respectively. The contour plot of bursting pressure concerning two factors $\mathrm{A}$ and $\mathrm{C}$ is shown in fig. 9. From the fig. 9, clear illustration with two factor effects can be found for obtaining lower bursting pressure. From the fig. 9, the limitations of the factors that give a better response output can be traced. In the present case, the limits for factor $\mathrm{A}$ and $\mathrm{C}$ is found to be 6-8.5 and 165200 respectively.

Table 11 ANOVA of the Bursting Pressure

\begin{tabular}{lrrrrrl}
\hline Source & DF & Adj SS & Adj MS & F-Value & P-Value & \% Contribution \\
\hline A & 2 & 0.06222 & 0.03111 & 1.82 & 0.188 & 1.01 \\
B & 2 & 0.00667 & 0.00333 & 0.19 & 0.825 & 0.11 \\
C & 2 & 5.61556 & 2.80778 & 164.09 & 0 & 98.78 \\
\hline
\end{tabular}




\begin{tabular}{lrrc}
\hline Error & 20 & 0.34222 & 0.01711 \\
Total & 26 & 6.02667 & \\
& & & Model Summary \\
S & R-sq & R-sq(adj) & R-sq(pred) \\
0.130809 & $94.32 \%$ & $92.62 \%$ & $89.65 \%$ \\
\hline
\end{tabular}

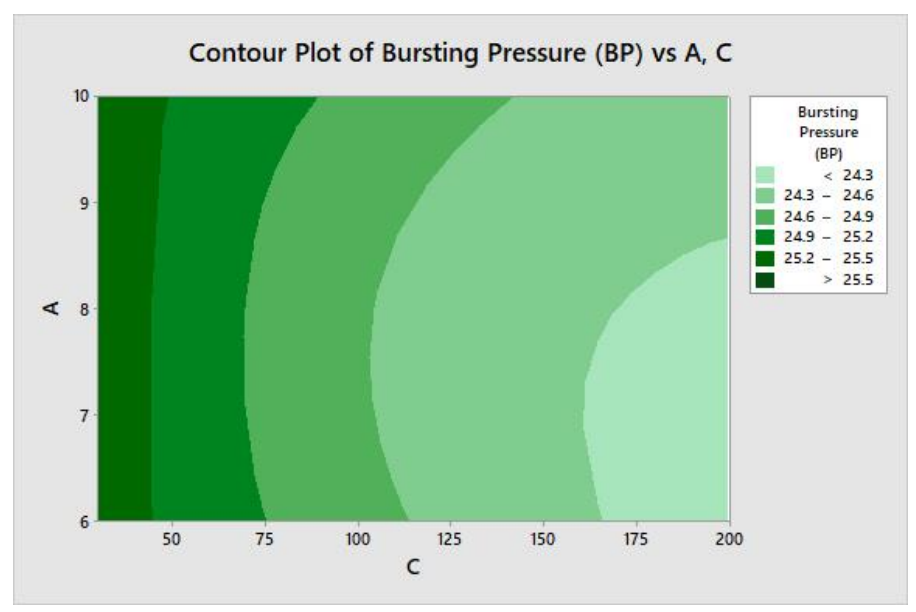

Fig. 9 Contour image of bursting pressure against two significant factors corner radius and heat treatment

\section{Conclusion}

The present work dealt with the process parameters selection for the bulging of the tubular component using the THF process by utilizing a decision model. The work utilized two MCDM methods, i.e., TOPSIS and PSI for ranking the alternatives based on the required criteria. The weighting of the responses to the TOPSIS method was carried out by Entropy method, whereas for PSI no such weighting method was utilized. All the alternatives were successfully evaluated by the two methods and the rankings were used to rank all the alternatives and compare the two MCDM methods. Both the MCDM methods suggested the same favorable and unfavorable alternatives i.e., test no \# 8 and \# 16 respectively. The combination of the best ranking was corner radius of $10 \mathrm{~mm}$, frictional coefficient of 0.12 and heat treatment temperature of $200^{\circ} \mathrm{C}$. The best and worst ranked alternatives were validated by conducting experimental trials as well. The experimental results were nearly the same as the numerical results. The present utilized MCDM models can be successfully used for any MCDM problems for the parameter selection out of various alternatives. ANOVA of the three responses suggested the significant variables to be factor $\mathrm{B}$ and $\mathrm{C}$ for bulge ratio, factor $\mathrm{A}$ and $\mathrm{B}$ for thinning ratio and factor $\mathrm{C}$ for the bursting pressure.

\section{Conflict of interest}

The authors declare that they have no conflict of interest. The authors declare that we have no known competing financial interests or personal relationships that could have appeared to 
influence the work reported in this paper. This article does not contain any studies with human participants or animals performed by any of the authors.

\section{Data Availability}

The data used to support the findings of the study are included within the manuscript.

\section{Acknowledgements}

The authors would sincerely like to thank the department of metallurgical engineering and material science at IIT Bombay for providing us the testing and computational facilities and authors would also like to thank the management of G Pulla Reddy Engineering College (Autonomous), Kurnool for providing the testing facilities and their constant support.

\section{Credit author statement}

P. Venkateshwar Reddy: Conceptualization, Methodology, Software, Writing- Original draft preparation. B. Veerabhadra Reddy: Investigation, Supervision, Validation.

\section{References}

[1].Dohmann, F., \& Hartl, C. Hydroforming-a method to manufacture light-weight parts. $J$ Mater. Process. Technol.1996, 60, 669-676.

[2].Lin, S. L.; Chen, Z. W.; \& Chen, F. K. A study on localized expansion defects in tube hydroforming. J Chin. Inst. Eng. 2018, 41, 149-159.

[3].Jorge, R. N.; Valente, R. A. F.; Roque, A. P.; Parente, M. P. L.; \& Fernandes, A. A. Numerical simulation of hydroforming process involving a tubular blank with dissimilar thickness. Mater. Manuf. Processes. 2007, 22, 286-291.

[4].Fann, K. J.; \& Hsiao, P. Y. Optimization of loading conditions for tube hydroforming. $J$ Mater. Process. Technol. 2003, 140, 520-524.

[5].Aue-U-Lan, Y.; Ngaile, G.; \& Altan, T. Optimizing tube hydroforming using process simulation and experimental verification. J Mater. Process. Technol. 2004, 146, 137-143.

[6].Lin, J. F.; Li, F.; \& Yuan, S. J. Optimisation of loading paths in hydroforming dissymmetrical part. Mater. Res. Innov. 2011, 15, s328-s330.

[7].Manabe, K. I.; Suetake, M.; Koyama, H.; \& Yang, M. Hydroforming process optimization of aluminum alloy tube using intelligent control technique. Int. J. Mach. Tool. Manu. 2006, 46, 1207-1211.

[8].Mohammadi, F.; Kashanizade, H.; \& Mashadi, M. M. Optimization using finite element analysis, neural network, and experiment in tube hydroforming of aluminium $\mathrm{T}$ joints. $P$ I Mech. Eng. B-J. Eng. 2007, 221, 1299-1305.

[9].Di Lorenzo, R.; Ingarao, G.; Gagliardi, F.; \& Filice, L. Experimental validation of optimisation strategies in hydroforming of T-shaped tubes. Int. J. Mater. Form. 2008, 1, 323-326. 
[10]. Abedrabbo, N.; Worswick, M.; Mayer, R.; \& van Riemsdijk, I. Optimization methods for the tube hydroforming process applied to advanced high-strength steels with experimental verification. J Mater. Process. Technol. 2009, 209, 110-123.

[11]. An, H.; Green, D. E.; \& Johrendt, J. Multi-objective optimization and sensitivity analysis of tube hydroforming. Int. J. Adv. Manuf. Tech. 2010, 50, 67-84.

[12]. Mirzaali, M.; Liaghat, G. H.; Naeini, H. M.; Seyedkashi, S. M. H.; \& Shojaee, K. Optimization of tube hydroforming process using simulated annealing algorithm. Proc. Engg. 2011, 10, 3012-3019.

[13]. Seyedkashi, S. M. H.; Naeini, H. M.; Liaghat, G. H.; Mashadi, M. M.; Mirzaali, M.; Shojaee, K.; \& Moon, Y. H. The effect of tube dimensions on optimized pressure and force loading paths in tube hydroforming process. J Mech. Sci. Technol. 2012, 26, 18171822.

[14]. Teng, B.; Li, K.; \& Yuan, S. Optimization of loading path in hydroforming T-shape using fuzzy control algorithm. Int. J. Adv. Manuf. Tech. 2013, 69, 1079-1086.

[15]. Brooghani, S. A.; Khalili, K.; Shahri, S. E.; \& Kang, B. S. Loading path optimization of a hydroformed part using multilevel response surface method. Int. J. Adv. Manuf. Tech. 2014, 70, 1523-1531.

[16]. Intarakumthornchai, T.; Aue-U-Lan, Y.; Kesvarakul, R.; \& Jirathearanat, S. Feasible pressure and axial feed path determination for fuel filler tube hydroforming by genetic algorithm. P I Mech. Eng. B-J. Eng. 2015, 229, 623-630.

[17]. Huang, T.; Song, X.; \& Liu, X. The multi-objective robust optimization of the loading path in the T-shape tube hydroforming based on dual response surface model. Int. J. Adv. Manuf. Tech. 2016, 82, 1595-1605.

[18]. Huang, T.; Song, X.; \& Liu, M. The multi-objective optimization of the loading paths for T-shape tube hydroforming using adaptive support vector regression. Int. J. Adv. Manuf. Tech. 2017, 88, 3447-3458.

[19]. Chebbah, M. S.; \& Lebaal, N. Tube hydroforming optimization using a surrogate modeling approach and Genetic Algorithm. Mech. Adv. Mater. Struc. 2018, 1-10.

[20]. Ying-ying, F.; Hong-ge, Z.; Zong-an, L.; \& Qing-lin, W. Loading path optimization of $\mathrm{T}$ tube in hydroforming process using response surface method. Int. J. Adv. Manuf. Tech. 2019, 101, 1979-1995.

[21]. Taguchi, G. Taguchi on robust technology development: bringing quality engineering upstream (Vol. 136). New York: ASME press, 1993.

[22]. Yuvaraj, N.; \& Pradeep Kumar, M. Multiresponse optimization of abrasive water jet cutting process parameters using TOPSIS approach. Mater. Manuf. Processes. 2015, $30,882-889$.

[23]. Manivannan, R.; \& Kumar, M. P. Multi-attribute decision-making of cryogenically cooled micro-EDM drilling process parameters using TOPSIS method. Mater. Manuf. Processes. 2017, 32, 209-215. 
[24]. Rao, R. V. Decision making in the manufacturing environment: using graph theory and fuzzy multiple attribute decision making methods. Springer Science \& Business Media, 2007.

[25]. Reddy, A. S.; Kumar, P. R.; \& Raj, P. A. Entropy-based fuzzy TOPSIS framework for selection of a sustainable building material. Int. J. Constr. Manag. 2019, 1-12.

[26]. Garg, H.; Agarwal, N.; \& Tripathi, A. Generalized intuitionistic fuzzy entropy measure of order $\alpha$ and degree $\beta$ and its applications to multi-criteria decision making problem. Int. J. Fuzzy Syst. 2017, 6, 86-107.

[27]. Sastry, C. C.; Hariharan, P.; \& Pradeep Kumar, M. Experimental investigation of dry, wet and cryogenic boring of AA 7075 alloy. Mater. Manuf. Processes. 2019, 34, 814831.

[28]. Maniya, K.; \& Bhatt, M. G. A selection of material using a novel type decisionmaking method: Preference selection index method. Mater. Des. 2010, 31, 1785-1789.

[29]. Renzi, C.; Leali, F.; \& Di Angelo, L. A review on decision-making methods in engineering design for the automotive industry. J. Eng. Design. 2017, 28, 118-143.

[30]. ASTM International. ASTM E517-00-Standard Test Methods for Plastic Strain Ratio $r$ for Sheet Metal, 2010.

[31]. ASTM International. ASTM E8/E8M-09 Standard Test Methods for Tension Testing of Metallic Materials. ASTM, 2011.

[32]. Reddy, P. V.; Reddy, B. V.; \& Ramulu, P. J. Mathematical modelling for prediction of tube hydroforming process using RSM and ANN. Int. J. Ind. Syst. Eng. 2020, 35, 1327.

[33]. Reddy, P. V.; Reddy, B. V.; \& Rao, P. S. A numerical study on tube hydroforming process to optimize the process parameters by Taguchi method. Mater. Today Proc. 2018, 5, 25376-25381.

[34]. Reddy, P. V.; Reddy, B. V.; \& Ramulu, P. J. Effect of heat treatment temperatures on formability of SS 304 during tube hydroforming process. SN Appl. Sci. 2020, 2, 205.

[35]. Reddy, P. V.; Reddy, B. V.; \& Ramulu, P. J. An investigation on tube hydroforming process considering the effect of frictional coefficient and corner radius. Adv. Mat. Process. Techn. 2020, 6, 84-103.

[36]. Zhang, H. P. Application on the entropy method for determination of weight of evaluating index in fuzzy mathematics for wine quality assessment. Adv. J. Food Sci. Tech. 2015, 7, 195-198.

[37]. Agrawal, D.; \& Kamble, D. Optimization of photochemical machining process parameters for manufacturing microfluidic channel. Mater. Manuf. Processes. 2019, 34, 17.

[38]. Singh, M.; Pant, M.; Godiyal, R. D.; \& Kumar Sharma, A. MCDM approach for selection of raw material in pulp and papermaking industry. Mater. Manuf. Processes. 2020, 35, 241-249. 
[39]. Gupta, M. K.; Sood, P. K.; Singh, G.; \& Sharma, V. S. Investigations of performance parameters in NFMQL assisted turning of titanium alloy using TOPSIS and particle swarm optimisation method. Int. J. Mater. Prod. Tec. 2018, 57, 299-321.

[40]. Petković, D.; Madić, M.; Radovanović, M.; \& Gečevska, V. Application of the performance selection index method for solving machining MCDM problems. Facta Univ., Ser. Mech. Eng. 2017, 15, 97-106. 